\title{
EL AUTOR Y SU IMAGEN: DIMENSIÓN DIALÓGICA DEL PROCESO DE TRADUCCIÓN DE UN TEXTO AUTOBIOGRÁFICO
}

\author{
María ANtonia Álvarez
}

To understand an author in the richest way, one must neither reduce him to an image of oneself, nor make oneself a version of him. (Bakhtin, 1990:56)

\section{O. INTRODUCCIÓN}

En un estudio del proceso de la traducción puede servir de ayuda una base teórica fundamentada en la dimensión dialógica de Mijail Bajtín, quien sostiene que un buen traductor no debe ocultarse detrás del autor original sino ocupar su lugar en esa situación dialógica que se establece entre autor-traductor. En su función de intérprete del texto escrito en una lengua extranjera a su lengua materna, no tienen por qué entrar en conflicto su lealtad al texto original y la que debe a sus lectores, la nueva audiencia a quien Bajtín llama superaddressees.

Este estudio del proceso de la traducción fundamentado en una base teórica bajtiniana resulta más productivo si se utiliza como contexto una obra autobiográfica, por la relación que existe entre la teoría de Mijail Bajtín sobre la conversación dialógica que se establece entre los términos $I$ (el autor) y you (la imagen del autor como protagonista) dentro del texto: 
The image of the author -if we are to understand by that the author-creator- is a contradiction in terms; every image is a created, and not a creating, thing. It goes without saying that the listener or reader may create himself an image of the author (and usually does, that is, in some way he pictures the author to himself); this enables him to make use of autobiographical and biographical material, to study the appropriate era in which the author lived and worked as well as other material about him. But in so doing he (the listener or reader) is merely creating an artistic and historical image of the author that may be, to a greater or lesser extent, truthful and profound that is, this image is subject to all those criteria that usually apply in these types of images. (1990:256-7)

\section{EXPERIENCIA LECTORA DEL TRADUCTOR}

En su ensayo «Discourse in the Novel» Bajtín presenta los puntos clave de su obra literaria The Dialogic Imagination, explicando su concepto de la experiencia lectora como algo que está ocurriendo o tiene lugar en un momento determinado, como una unión o compenetración entre el lector y el texto. Según el concepto de dialogía de Mijail Bajtin, un autor -incluído el traductordirige sus palabras e imágenes directamente a un lector «whose absolutely just responsive understanding is presumed, either in some metaphysical distance or in distant historical time.» (1990:135) La lectura siempre tiene lugar en una determinada situación (un lector concreto de un texto concreto en un tiempo y lugar concretos) y si se cambia alguno de estos elementos resulta algo totalmente diferente:

The outside world becomes determinate and concrete for us only through our willed relationship to it; in this sense, our relationship determines an object and its structure, and not the other way around. (1990:180)

No obstante, si todas las cosas forman parte de un todo, con una constante interacción entre significados y capacidad para condicionarse unos a otros, los términos yo y tú se unen en el discurso (el lector, como yo individual, se une al tú del texto).

En una situación dialogica, el traductor lee un texto y recrea su lectura en otra lengua para un futuro lector de otra cultura. Por tanto, la traducción comienza en la experiencia lectora del traductor, y sigue en la transacción dialógica entre el lector y la obra. Sin embargo, ningún autor puede estar seguro de 
que su mensaje ha sido fielmente interpretado, pues cada lector aporta su schemata (sus propios conocimientos y personalidad) a esa situación concreta, y en su esfuerzo por comprender, tiene que interpretar el texto y también al autor, su vida y su obra: comprender implica no sólo descodificar un mensaje, sino la unión de diversos niveles -lectores, autores, intérpretes- pues en la experiencia lectora no sólo está implicado el texto, sino el escritor, el lector, el contexto, y también el pasado, el presente y el futuro.

Bajtín diferencia asimismo la lectura activa de la pasiva, afirmando que cuando el lector busca respuestas comprende de forma activa, asimila «the word under consideration into a new conceptual system, that of the one striving to understand.» (1990:282) La comprensión activa precisa unir lo que se va a comprender con las nuevas aportaciones de quien lo comprende, precisa diversas respuestas complejas y efectuar elecciones sobre si se está o no de acuerdo con el mensaje; de ahí que diversos lectores den continuamente un significado nuevo al texto, e incluso un mismo lector, en nuevas situaciones, puede dar un nuevo significado al mismo texto.

La comprensión activa es enriquecedora, creativa y productiva, cambiante y abierta: «nothing conclusive has yet taken place in the world, the ultimate word of the world and about the world has not yet been spoken, the world is open and free, everything is still in the future and will always be in the future.» (1987:166) La comprensión pasiva, sin embargo, sólo significa la recepción de algo dado y preparado de antemano, convirtiéndose en un modelo repetitivo.

La teoría de Mijail Bajtín sobre la dimensión dialogica también puede aplicarse a la traducción como proceso, donde diferentes voces se unen al mismo nivel y podemos oír el $t u$ y el yo del autor y del lector, así como del traductor como lector-autor quien, al realizar su función, juega un papel renovador en la interpretación textual, por ser el creador de un nuevo texto y de una nueva situación. En esa interacción dialógica con su autor y sus futuros lectores, el traductor tiene que ser fiel a ambos; es decir, tanto al interpretar el texto original como al producir su nuevo texto.

Si se trata de un texto literario, el traductor tiene que intentar conseguir una versión créble, no sólo traduciendo el mensaje contenido, sino también la situación, siendo un fin primordial conocer las diferentes clases de lectores que tendrán acceso al nuevo texto. La situación de traducir textos literarios puede contemplarse desde distintos ángulos: podemos estar interesados en diferentes géneros de literatura, en comparar diversas culturas, en estudiar la reacción de los lectores, en la evolución de las versiones de una misma obra en distintas épocas, en la política seguida para la selección de obras que han de ser traducidas, etc. Por ejemplo, en la traducción de libros infantiles lo que le interesa a Riitta Oittinen resaltar es la importancia del diálogo que 
se establece entre texto-ilustración, no pudiendo separarse ambos elementos por ser una mezcla de similitud y diferencia que viven uno al lado del otro: «they are, however, also part of a greater whole: the dialogics of the original work and its translations, especially the dialogics of the various individual readers in different cultures.» (1993:113)

\section{LA IMAGEN DEL AUTOR EN EL TEXTO AUTOBIOGRÁFICO}

Si centramos nuestra atención en la escritura autobiográfica, resulta muy útil la teoría sobre la dimensión dialógica desarrollada por Mijail Bajtín, pues el autor no puede identificarse totalmente con el personaje principal, ya que está fuera de ese tiempo concreto que narra; es decir, la acción que describe ya tuvo lugar en otro tiempo y espacio diferentes, encontrándose él fuera del tiempo y del espacio en que ésta ocurrio:

If I relate (or write about) an event that has just happened to me, then I as the teller (or writer) of this event am already outside the time and space in which the event occured. It is just as impossible to forge an identity between myself, my own I, and that I that is the subject of my stories as it is to lift myself up by my own hair. The represented world, however realistic and truthful, can never be chronotopically identical with the real world it represents, where the author and creator of the literary work is to be found. That is why the term image of the author seems to me so inadequate: everything that becomes an image in the literary work, and consequently enters its chronotopes, is a created thing and not a force that itself creates. (1990:256-7)

Para ilustrar esta teoría de Mijail Bajtín podemos analizar la Autobiografia de Benjamín Franklin, quien crea y consigue mantener a lo largo de la obra un personaje que puede colocarse entre los más significativos de la literatura norteamericana. Bajtín afirma que el autor jamás se identifica con el protagonista en la escritura autobiográfica; por tanto, cuando Franklin relata lo que le ha ocurrido, ya se encuentra lejos del tiempo y el espacio en que esa acción ocurrio, por lo que es imposible identificar su propio yo con el personaje principal de la historia. El mundo representado, a pesar de que sea realista y auténtico, nunca podrá ser idéntico al mundo real que representa, donde hay que encontrar al autor y creador. Por ello le parece inadecuado a Bajtín hablar de imagen del autor ya que todo aquello que se convierte en imagen dentro de una obra literaria es algo creado y no una fuerza creadora. 
El genero autobiográfico no es el único al que Franklin dedicó sus tareas de escritor. Sería imposible relacionar aquí todas sus obras entre las que figuran innumerables ensayos, multitud de cartas, folletos, discursos y artículos, aunque sin duda la más conocida sea su Autobiografía, cuya primera parte, que está dirigida a su hijo, comenzó a escribirla en casa de su amigo el Obispo de Asaph (Twyford, Inglaterra) en agosto de 1771 , cuando ya tenía sesenta y cinco años de edad y podía ofrecer su propia vida como ejemplo a seguir: «en la creencia de que te pueda resultar asimismo agradable conocer las circunstancias de mi vida - muchas de las cuales desconoces-, pensando en tí me dispongo a escribirlas.» La segunda parte la escribió en Francia unos trece años más tarde y es la más interesante de toda la obra, pues en ella expone la base de sus ideas morales, que está convencido pueden conducir fácilmente a la felicidad. Y la tercera la inicí cuatro años después (1788) en Filadelfia, donde también escribió la cuarta parte a los ochenta y cuatro años, cuando estaba ya gravemente enfermo, por lo que no logró completarla, interrumpiéndose el relato en los acontecimientos de su vida ocurridos en el año 1757.

El tiempo, el lugar y la situación adquieren gran importancia en la teoría de Bajtin, así como las diferencias entre lectores y oyentes, siendo el diálogo una especie de contexto o una situación que tiene lugar entre el texto, el lector y su entorno (la cultura, el tiempo y el espacio). Vista la Autobiografía de Franklin desde nuestra perspectiva de finales del siglo $\mathrm{XX}$, cuando el mundo se mueve de una manera diferente al XVIII, no resulta extraño el rechazo de esta moralidad estrecha que presenta como modelo. No obstante, puede ser ahora tan relevante como lo fue en su tiempo, ya que todavía siguen siendo necesarios el trabajo y la confianza en sí mismo para poder conseguir una sociedad fuerte y sana, y también resulta aún significativo el ejemplo que ofrece de autodidacta, recordándonos la satisfacción que se deriva de una buena lectura y de ensanchar y profundizar nuestro conocimiento y nuestras facultades mentales, colocando en el punto más alto de una escala de valores el placer y los beneficios que produce tanto el estudio individual como el intercambio de ideas con otros hombres.

Entre los aspectos más importantes de la Autobiografia están sin duda el de haber sido escrita como guía moral para los jóvenes, a fin de mostrarles como poder llegar a tener éxito en la vida, presentar un carácter inconfundiblemente norteamericano y transmitir a sus compatriotas la convicción de que cualquier hombre que se lo propusiera podía mejorar su situación social. Franklin se ofrece como una figura representativa de América, identificándose totalmente con su país. De esta manera, personifica el prototipo del ciudadano norteamericano, transformando su Autobiografia en un tratado para ascender de posición social, pues está convencido de que América podía ser mejor que 
el viejo continente y ofrecer más fácilmente la posibilidad de progresar, ya que el trabajo garantizaba el éxito.

\section{Dimensión dialógica del PROCESO de TRADUCCIÓN}

Este mensaje que Franklin transmite a sus lectores ha de ser fielmente interpretado por el traductor literario quien, en primer lugar, es un lector que aporta la dimensión de sus conocimientos de la lengua, la literatura y la cultura a la experiencia lectora. Por ello, al acercarse a un texto literario para comprenderlo e interpretarlo, el traductor se convierte en un intérprete activo de esa obra artística, que en este caso supone interpretar la doctrina de la llustración que defendía el interés del propio individuo, lo que representa un cambio importante sobre las ideas de los Puritanos, pues propugna que el conocimiento de nuestros propios intereses -incluso en este mundo- nos conduce a la virtud. Por eso Franklin incluye, como parte central de su obra, una lista de doce virtudes: Templanza, Silencio, Orden, Resolución, Frugalidad, Sinceridad, Justicia, Moderación, Limpieza y Castidad, explicando el método que va a seguir:

My Intention being to acquire the Habitude of all these Virtues, I judg'd it would be well not to distract my Attention by attempting the whole at once, but to fix it on one of them at a time, and when I should be Master of that, then to proceed to another, and so on till I should have gone thro' the thirteen.

Siendo mi intención adquirir el hábito de todas estas virtudes, juzgué que seria necesario no distraer mi atención intentándolas todas a la vez, sino fijarla de una en una y, cuando dominara tsa, entonces seguir con otra, y así sucesivamente, hasta conseguir las trece.

Al explicar su gran esquema para lograr ese Arte de la Virtud -que supone para él una religión nueva y mejor- expresa de manera sucinta su filosofía, centrada en su fe en el individuo. Esta es una filosofía que permite conseguir logros importantes a la humanidad, como supuso la creación de la primera biblioteca de préstamo en Norteamérica. Franklin estaba convencido de la eficacia de la acción (libertad vs determinismo) y creía que cualquier individuo, tanto si se trataba de emitir un voto como de realizar el trabajo diario, podía cambiar los acontecimientos de la historia, como había hecho él, ya que «lo más difícil es ganar las primeras cien libras».

Según Bajtín, toda palabra nace en un diálogo, y en esa determinada situación, la palabra, el mensaje, la lengua o la cultura son dialogizadas o rela- 
tivizadas con otra palabra, mensaje, lengua o cultura. El diálogo es siempre indicativo, no autoritario, y puede ser interno y externo. Tiene lugar entre personas, pero también entre personas y cosas; en cualquier caso, siempre está implicado un ser humano, que puede estar leyendo o viendo las ilustraciones: al leer hay un diálogo entre el lector y el libro, y por extensión, el autor. El diálogo también puede tener lugar dentro de una persona: cuando el traductor está creando una versión para amantes de la literatura, tiene que procurar reflejar en ella no sólo el sentido, sino también todos los elementos estilísticos que contiene el original e incluso el tono del autor, a fin de no desvirtuar su carácter artístico. En la Autobiografía de Franklin está implícita su creencia optimista en que los problemas complejos se resuelven con la razón, la cooperación y el buen deseo, y no puede obviarlo el traductor. Esta es una filosofía de esperanza, incluso de optimismo, y por eso las reglas esenciales de conducta de Franklin pueden enumerarse en el siguiente orden: percibir una necesidad vital en la sociedad, desarrollar el plan para resolverla, preparar la mentalidad de sus conciudadanos por medio de escritos, y, a continuación reunir fondos, iniciar el proyecto y observar cómo va avanzando su realización: el plan para obtener la perfección moral, tema principal de la Autobiografía, es un claro ejemplo de la fe de Franklin en las normas, la disciplina y el método, limitando la esfera del conocimiento humano a lo que la Razón podía comprender. Este cuidado continuo en no distraer su atención del camino que se había propuesto seguir es una obsesión durante toda su vida, según va contando a través de la obra:

But I soon found I had undertaken a Task of more Difficulty than I had imagined. While my Attention was taken up in guarding against one Fault, I was often surpris'd by another. Habit took the Advantage of Inattention. Inclination was sometimes too strong for Reason. For this purpose I therefore contriv'd the following Method.

Pronto me di cuenta de que había emprendido una tarea más difícil de lo que habra imaginado. Mientras mi atención se ocupaba de estar en guardia contra una falta siempre me sorprendía otra. El hábito se aprovechaba de la falta de atención. La inclinación era a veces demasiado fuerte para la razón. Por tanto, con este proposito, concebí el método que incluyo.

De esta manera, Franklin produce el primer código moral de Norteamérica, que puede llevarse a cabo por medio de una actitud pragmática y, por ello, su Autobiografia se considera una de las principales obras clásicas de la literatura norteamericana: 
From the Attributes of God, his infinite Wisdom, Goodness \& Power concluded that nothing could possibly be wrong in the World, \& that Vice \& Virtue were empty Distinctions, no such Things existing: appear'd now not so clever a Performance as I once thought it... I grew convinc'd that Truth, Sincerity \& Integrity in Dealing between Man \& Man, were of the utmost Importance to the Felicity of Life, and I form'd written Resolutions, (which still remain in my Journal Book) to practice them ever while I lived.

Por los atributos de Dios — su Sabiduría, Bondad y Poder infinitivos - llegué a la conclusión de que posiblemente no habŕa nada malo en el mundo, y que el Vicio y la Virtud eran conceptos vacíos, no existiendo tales cosas y no pareciéndome ahora una práctica tan sabia como creia antes... Llegué al convencimiento de que la Verdad, la Sinceridad y la Integridad en las relaciones entre los hombres eran sumamente importantes para ser felices en la vida, y formule por escrito unos propósitos (que aún están en mi Diario) para practicarlos mientras viviera.

Su clave está en proyectar el futuro de América, y para conseguirlo Franklin se desplaza desde la ideología puritana a una nueva, secular y pragmática, a fin de conseguir su principal objetivo de captar la atención del lector con su historia. Es consciente de lo que ha conseguido en el mundo por su propio esfuerzo, como máxima expresión del sueño americano: éxito material, perfección moral y progreso social. Antes de llegar a la edad madura ya había reunido una fortuna, a pesar de sus orígenes humildes, lo que le permitió la libertad necesaria para poder dedicarse durante el resto de su vida a los estudios filosoficos y a sus propias inclinaciones. No obstante, en la Autobiografía el éxito económico conseguido no es más que un tema secundario. Cuando se refiere a él, Franklin lo hace únicamente para resaltar algunos aspectos, como puede ser su frugalidad. Este aspecto lo ilustra claramente la anécdota sobre la cuchara de plata y la taza de porcelana que un día le compró su mujer sin su conocimiento, negándose él rotundamente a utilizarlas. En realidad, Franklin repite sin cesar que sus padres eran pobres: «...habiendo ascendido desde la Pobreza y Oscuridad en que nací y me crię», pero rara vez menciona la riqueza que consiguió; sólo en algún pasaje explica: «logré un Estado de Riqueza», añadiendo a continuación «y cierto Grado de Reputación en el Mundo.» Lo que le interesa principalmente resaltar es su salida de la oscuridad para conseguir reputación dentro de la sociedad, a fin de animar a todo americano que le lea a elegir los medios para lograrlo, basados en el sentido común y el trabajo individual: 
I began now gradually to pay off the Debt I was under for the Printinghouse. In order to secure my Credit and Character as a Tradesman, I took care not only to be in Reality Industrious \& frugal, but to avoid all Appearances of the Contrary. I dressed plainly; I was seen at no Places of idle Diversion; I never went out a-fishing or Shooting; a Book, indeed, sometimes debauch'd me from my Work; but that was seldom, snugh, \& gave no Scandal.

Ahora comence gradualmente a pagar las deudas que había adquirido por la imprenta. A fin de asegurar mi crédito y reputación como comerciante, tuve cuidado no s6lo de ser realmente laborioso y frugal, sino de evitar toda apariencia de lo contrario. Vestra con sencillez y no se me veía en lugares de diversión frivola; no iba nunca de caza o pesca; claro está que a veces un libro me apartaba del trabajo, pero esto ocurria rara vez, y descansaba sin producir escándalo.

El tema del sueño americano otorga a la obra mucho de su significado alegórico y de su poder arquetípico, pues el desarrollo de Franklin, quien se convirtió a finales del siglo XVIII en el hombre más famoso del mundo occidental, tiene su contrapartida en el desarrollo de los Estados Unidos, y él es consciente de ello. De ahí que la sociedad norteamericana no se acerque a la Autobiografía por su sátira sobre la naturaleza del hombre, sus importantes contribuciones a las cuestiones clave de la filosofía ética y moral que acaparaban el pensamiento del siglo XVIII, o su escepticismo sobre las diversas doctrinas religiosas. Sin duda estos temas añaden profundidad a su grandeza, riqueza y complejidad a su pensamiento, textura y sutileza a su lenguaje, pero su popularidad se debe a que en ella explica Franklin minuciosamente cómo puede utilizar cualquier ciudadano de los Estados Unidos la herencia recibida y, a partir de ella, modelar su vida dentro de un modelo nuevo y revolucionario, subrayando la importancia del trabajo, la sobriedad y la economía como fines seguros para conseguir los conocimientos útiles necesarios que le permitirian al hombre su independencia:

...it was my Design to explain and enforce this Doctrine, that vicious Actions are not hurtful because they are forbidden, but forbidden because they are hurtful, the Nature of Man alone consider'd: That it was therefore every one's Interest to be virtuous, who wish'd to be happy even in this World.

...era mi intención explicar y reforzar esta doctrina, que las malas acciones no son perjudiciales porque estén prohibidas, sino prohibidas porque son perjudiciales únicamente teniendo en cuenta la naturaleza humana; que por tanto interesaba ser virtuoso a todo el que también quisiera ser feliz en este mundo. 
Franklin trabajo sin descanso para perfeccionar su carácter y para acrecentar su formación intelectual, aprendiendo solo a leer francés, español, italiano y latín. Para mejorar su retórica fundó en 1727 el club Junto, un club de debate dedicado a la moral, la política y la filosofía natural. Fue líder de muchos movimientos que perseguían el beneficio de su comunidad y, en el tiempo libre que le permitían sus diversas actividades, se dedicó al estudio de las ciencias (por ejemplo, sus experimentos con la electricidad, etc.).

En cuanto a los elementos formales, la Autobiografia posee unidad y hasta cierta complejidad, pues Franklin crea de forma deliberada una especie de visión novelística e incorpora esa visión a escenas inolvidables. Por tanto, aunque según J.A. Leo Lemay (1978:21) estilísticamente la Autobiografia no tenga la misma perfección estructural que puedan tener Los embajadores, de Henry James o La carta escarlata, de Nathaniel Hawthome, ni posea el lenguaje grandilocuente de Melville, Whitman o Faulkner, esta obra -mezcla de los estilos epistolar y narrativo que refleja las limitaciones de su época- sigue utilizándose como libro de texto en la escuela y en la universidad, y es un documento de la historia social y cultural de los Estados Unidos que muchos siguen leyendo por puro placer.

\section{Conclusión}

Aunque el concepto tradicional de traducción consideraba su proceso como un acto mecánico, relegado a la oscuridad y basado en los conceptos de equivalencia y fidelidad, los nuevos acercamientos a la teoría de la traducción consideran que es esencial tener en cuenta los conceptos de situación y proposito de la traducción. Por tanto, en la Autobiografía de Franklin, el traductor tiene que tener presente la importancia del sueño americano - tema básico de esta obra - tanto para la literatura de ese país como para sus habitantes, basado en la popularidad del self-made man y en la certeza de que cualquier niño norteamericano podrá conseguir un estado glorioso de libertad e independencia cuando sea adulto, pudiendo llegar incluso a cambiar el mundo. En general, el sueño americano es la esperanza por conseguir un mundo mejor, un mundo democrático ideal que permita elegir todo lo que se quiera en la vida; un mundo nuevo libre de todas las lacras que tenía el viejo. Y esta es la función básica de la Autobiografía de Franklin: demostrar que el hombre puede elegir y crear lo que desee, de tal forma que esa esperanza individual permita triunfar a seres humanos muy diversos, si creen en la posibilidad de conseguirlo. También es esencial la parte moralizante, y su verdadera razón para escribirla, a fin de presentar a la sociedad norteamericana su plan para obtener la 
perfección moral, que proyectaba desarrollar algún día en un Arte de la Virtud, donde tenía la intención de explicar y reforzar su doctrina. Y si la Autobiografia de Franklin se ha convertido en un documento tan importante que se considera el libro más típicamente americano es porque todos sus valores los ha hecho suyos la sociedad: el americano medio se ha identificado con la figura de Benjamín Franklin y ha tratado de vivir de acuerdo con sus enseñanzas para conseguir esos logros que el autor describe.

No obstante, de acuerdo con la teoría de Bajtín, la imagen del autor - si hemos de entender con ello el autor-creador- es una contradicción en cuanto al término que se le aplica, pues una imagen es una cosa creada, no creadora. Es obvio que el traductor puede crear su propia imagen del autor (normalmente así lo hace; es decir, de alguna manera se crea la imagen de Benjamín Franklin para sî) y esto le permite utilizar material autobiográfico y biográfico para estudiar la época en que el autor vivió y trabajo, aś como otros materiales sobre él. Pero al hacerlo, está simplemente creando una imagen artística e histórica de Franklin, que puede ser en mayor o menor medida verdadera y profunda si sabe interpretar todo lo que se dice en el texto y después expresarlo en su lengua materna, pues - como afirma Mijail Bajtín- no tienen por qué entrar en conflicto su lealtad al texto original y a sus lectores, ni tampoco tiene el traductor que ocultarse detrás del autor original, sino ocupar su lugar en esa situación dialogica que se establece entre autortraductor.

\section{Biblografia}

ALDRIDGE, A. OWEN (1967) «Form and Substance in Franklin's Autobiography», Essays on American Literature, ed. Clarence Gohdes. Durham, N.C.: Duke University Press.

Bakhtw, Mrkhall (1987) Problems of Dostoevsky's Poetics, ed. \& trad. Caryl Emerson. Minneapolis: University of Minnesota.

- (1990) The Dialogic Imagination: Four Essays, ed. Holquist. Austin: University of Texas Press.

BARBoUR, Brian M. (ed.) (1979) Benjamin Franklin: A Collection of Critical Essays. Englewood Cliffs, NY: Prentice-Hall \& Co.

Dawson, Hugh J. (1979-80) «Fathers and Sons: Franklin's 'Memoirs' as Myth and Metaphor», Earty American Literature 14, págs. 27-42.

GRIFFTH, JOHN (1971) «The Rhetoric of Franklin's Autobiography», Criticism 13.

- (1976) «Franklin's Sanity and the Man Behind the Masks», The Oldest Revolutionary: Essays on Benjamin Franklin, en Lemat, ed. cit. 
Franklin, Benjamin (1986) Autobiography: An Authoritative Text, ed. J.A. Leo Lemay \& P.M. Zall. New York/London: Norton (las citas de esta edición están traducidas por $\mathrm{m}$ ).

- (1986) Autobiography and Other Writings, ed. \& intr. Kenneth Silverman. New York/Harmondsworth: Penguin Books.

- (1986) Benjamin Franklin's The Art of Virtue: His Formula for Successful Living. Eden Prairie, Minn: Acorn Pub.

ILIE, PAUL (1973) «Franklin and Villarroel: Social Consciousness in Two Autobiographies», Eighteenth-Century Studies, 7, pp.321 -42.

LEMAY, J.A. Leo \& G.S. Rouseau (1978) The Renaissance Man in the Eighteenth Century. Los Angeles: University of California.

- (ed.) (1976) The Oldest Revolutionary: Essays on Benjamin Franklin. Philadelphia: University of Pennsylvania Press.

LeVIN, DAVID (1979) «The Autobiography of Benjamin Franklin: The Puritan Experimenter in Life and Art», en Barbour, ed. cit.

Lope, Claude-Anne \& Herbert, Eugenia W. (1975) The Private Franklin. New York: W.W. Norton \& Company, Inc.

LÓPEZ GUERRA, LUIS (1982) Introducción a Benjamín Franklin: Autobiografía y otros escritos. Madrid: Editora Nacional.

OITINEN, RIITA (1993) I am me - I am other: On the Dialogics of Translating for Children. Finland: University of Tampere

SAYRE, ROBERT F. (1964) The Examined Self: Benjamin Franklin, Henry Adams, Henry James. Princeton: Princeton University Press. 